\title{
خصائص اللغة العربية وخاصة بالمقارنة باللغة الإندونيسية (في المباني الصرفية والتراكيب النحوية والمعاني الدلالية)
}

\author{
Isra Hayati Darman \\ STAIN Mandailing Natal, Sumatera Utara, Indonesia \\ email: israhayatid@gmail.com
}

\begin{abstract}
Abstrak
Penelitian ini membahas tentang karakteristik bahasa Arab khususnya jika dibandingkan dengan bahasa Indonesia. Melalui analisis perbandingan praktis antara bahasa Arab dan bahasa Indonesia, tulisan ini dapat mempermudah para guru dalam proses pembelajaran bahasa Arab terhadap siswa Indonesia. Tujuan penelitian ini secar rinci adalah untuk membahas karakteristik bahasa Arab dari aspek morfologi, sintaksis dan semantik, lalu dibandingkan secara ringkas dengan bahasa Indonesia. Penelitian ini merupakan studi pustaka dengan menggunakan metode deskriptif analitis dengan pendekatan kualitatif. Hasil dari penelitian ini adalah: (1) Karakteristik bahasa arab dari segi morfologinya antara lain berupa fenomena isytiqaq, tashrif, shiyagh, muthabaqah fi al-siyagh (dari segi al-syakhshu, adad, nau', dan tayin). (2) Karakteristik bahasa Arab dari segi sintaksisnya antara lain fenomena i'rab, bentuk kalimat dan gaya bahasa yang bermacam-macam serta muthabaqah dalam susunan sintaksisnya. (3) Karakteristik bahasa Arab dari aspek semantik dilihat dari tiga aspek, pertama makna dari aspek bunyi berupa fonem, morfem, stressing dan intonasi, kedua makna dari aspek morfologi berupa taraduf, musytarak al-lafzhi dan tadhad, dan ketiga, makna dari aspek sintaksis dan gaya bahasa atau pragmatik.
\end{abstract}

Kata kunci: karakteristik, bahasa Arab, morfologi, sintaksis, semantik.

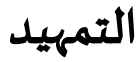

اللغة العربية لغة خاصة في العالم. لها خصائص ومميزات الكثيرة إذا نقارن

بكل اللغات في العالم. يعد اللغة العربية من أقدم اللغات في العالم. والآن قد اصبحت اللغة العربية احدى اللغات المكتوبة كاللغات العالمية في أمم المتحدة. وهي لغة الدين، اللغة لكل أمة الإسلام في العالم، اللغة التي يستخدمها المسلمون كل يوم في الصلاة والذكر والدعاء. واللغة العربية مشهورة بلغة الضياد، لأن لها حرفا خاصيا الذي لا يوجد في أي لغات في العالم، وهو حرف الضياد. أسلوب اللغة العربية معروفة بجمالها ومعناها العميق. 
Isra Hayati Darman: Khașāiṣ al Lugah al 'Arabiyyah wa Khāsșah bi al Muqāranah bi al Lugah al Indūnisiyyah (Fĩ al Mabānī al Șarfiyyah wa al Taräkīb al Naḥwiyyah wa al ma'anny al Dilāliyyah

ومن مميزات اللغة العربية إذا نقارن باللغات الأخرى أن لها لغة الفصحة الواحدة. وهذا الحال يختلف بهيئة اللغات الأخرى كالإنجليزية مثلا، لها عدة الأنماط من لغة الفصحة، ويدل هذا الحال أن الناطقين بهذه اللغة لا يتحدون ولا يتفقون في لغة واحدة. ومن أسباب هذه الخصائص هي أن اللغة العربية هي لغة القرآن التى سيحفظها الله حتي يوم الآخر. كما يحفظه القرآن الكريم. قال الله تعالى في السورة الحجر: 9 (( إنا نحن نزّلنا الذكر وإنا له لحافظون)). فبحفظ القرآن سيحفظ لغتاه حتى يوم القيامة. كما قال رشـدي أحمد طعيمة' أن الإلمام بخصيائص اللغة لله أهمية وخاصية لمعلم اللغة الثانية. وعلى المعلم أن يكون على علم بخصائص هذه اللغة وما يميزها عن غيرها من اللغات. وهذا من شأنها أن يساعده: (1) على تقديم المادة اللغوية المناسبة، (Y) على تعرف مواطن الصعوبة أو السهولة المتوقعة عند تعليم هذه اللغة لأبناء لغتاه، (r) على إجراء دراسـات حول التقابل اللغوي بين هذه اللغة وغيرها من لغات، (ع) على توضيح نظام اللغة وشرحاه لطلاب المستويات المتقدمة في برامج تعليمها للناظقين بلغات أخرى، و(0) على فهم الظواهر اللغوية المختلفة

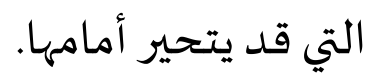

تذكر الخصائص الكثيرة من اللغة العربية، ولكن سيحدد البحث في هذه خاصية عن خصائص اللغة العربية في المباني الصرفية والتراكيب النحوية والمعاني الدلالية بالمقارنة باللغة الإندونيسية. ويهدف هذه المقارنة لتسهيل عملية التعليم العربية للطلاب الإندونيسيين حتى يتحقق النجاح في تعليم هذه اللغة الكريمة.

\section{منهج البحث}

رشدي أحمد طعيمة، تعليم العربية لغير الناطقين بها مناهجه واساليبه (الرباط: منشوات المنظمة الإسلامية للتربية والعلوم والثقافة-ايسيسكو-، 1989)، ص. صدم 35 

Lugah al Indūnisiyyah (Fĩ al Mabānī al Șarfiyyah wa al Taräkīb al Naḥwiyyah wa al ma'anny al Dilāliyyah

هذا البحث هو البحث المكتبي، يعني بدراسـة عدة الكتب العربية التي تتعلق بهذا البحث. تستخدم الباحثة المنهج الوصفي التحليلي بمدخل البحث الكيفي. يعني بوصف كل ما يتعلق بخصائص اللغة العربية في المباني الصرفية والتراكيب النحوية والمعاني الدلالية ثم تقارنها باللغة الإندونيسية بالأمثلة والتحليل.

\section{البحث والنتائج}

\section{خصائص العربية في المباني الصرفية مقارنة باللغة الإندونيسية}

1. 1 لغة اشتقاق

إن ظاهرة الاشتقاق أكثر وضهوحا في العربية. والاشتقاق معناه أن للكلمة أصول (جذر stem)، وأنها تتمثل في عائلة من الكلمات بعضها أفعال وبعضها أسماء وبعضها صفات. ومن هذا الجذر نستطيع بناء عدد كبير من الكلمات. الاشتقاق لغة: أخذ شق الشيء وهو نصفاء، أو الاشتقاق الحرف من الحرف

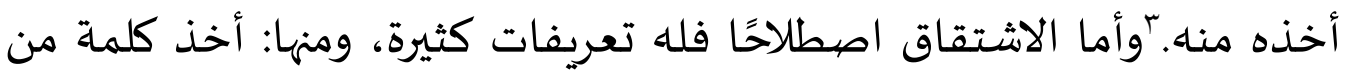

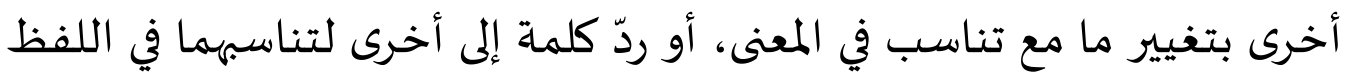

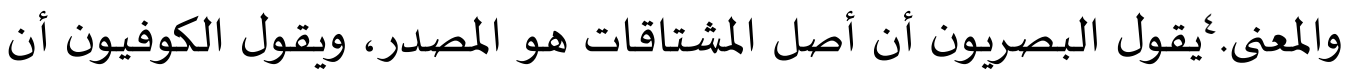
أصل المشتقات هو الفعل. وللاشتقاق انواع، وهي:

\section{أ) الاشتقاق الصغير أو أصغر}

هو نزع اللفظ من آخر بشرط اشتراكهما في المعنى والأحرف الأصلية وترتبيها. مثلا: اشتقاق اسم فاعل "ضيارب" واسم مفعول "مضروب" من فعل مل مل

r رشدي أحمد طعيمة، تعليم العربية لغير الناطقين بها مناهجه واساليبه ...، ص. 36

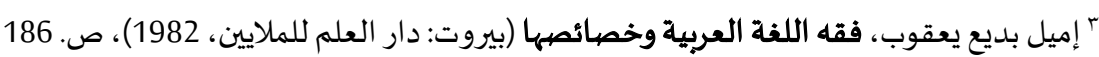
؛ إميل بديع يعقوب، فقه اللغة العربية وخصائصها ...، ص. 187 

Lugah al Indūnisiyyah (Fĩ al Mabānī al Șarfiyyah wa al Taräkīb al Naḥwiyyah wa al ma'anny al Dilāliyyah

"ضرب" أو من مصدر "ضرب". فهذ الكلمات تشترك في المعنى والأحرف الأصلية وترتيبها. ب) ب الاشتقاق الكبير

يسمى أيضيا القلب اللغوي: وهو يقع بين الكلمتين تناسب في اللفظ والمعنى دون ترتيب الحروف. مثلا: "حمد" و"مدح"، ولهما نفس المعنى ولكن هناك القلب بين ترتيب حروفها. وكذلك لفظ "جذب" و "جبذ". ج) الاشتقاق الأكبر ويسمى بابدال اللغوي، وهو ابدال حرف من الكلمة بحرف آخر وارتباط معان ارتباطا عاما بدون تغيير الترتيب. مثلا: "طنّ" و"دنّ"، "نعق" و"نهق"،

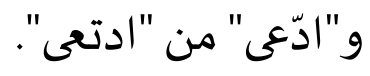

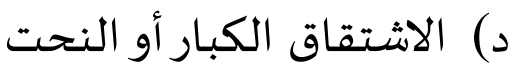

هو أن ينتزع من كلمتين أو أكثر كلماة جديدة تدل على معنى ما انتزعت

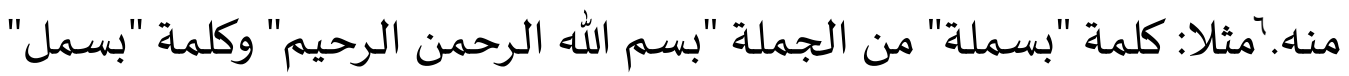
من " أن يقول بسم الله الرحمن الرحيم"، وكذلك "حمدلة" و"حمدل" و"حولق" و"حسبل" و"سمعل" وغيرها. واختلف العلماء في أن النحت نوع من الاشتقاق، وكثير منهم لا يتفقون فياه. وأما الكاتبة تتفق بما رآه الجمهور، لأن النحت يأخذ من كلمتين أو أكثر، أما الاشتقاق يأخذ من الكلمة الواحدة. ولماه. أما في اللغة الإندونيسياة، يوجد النوع الأول من الاشتقاق، فهي اشتقاق لهاق melihat dilihat " "lihat"، ثم تشتق منها الكلمات مثلا: الكلمة الأصلية ." kelihatannya penglihatan melihat-lihat م إميل بديع يعقوب، فقه اللفة العربية وخصائصها ...، ص. 198 7 
وأما النحت في اللغة العربية يشاباه ب"akronim" في اللغة الإندونيسية.

ولكن الشكل بين النحت و "akronim" يختلف. أكثر akronim " في اللغة الإندونيسية يؤخذ من الحروف الأولى لكل كلمة في الكلمات المقصودة، وهو ليس بشكل الجملة كالنحت في اللغة العربية، ولكن الاسم لاشياء فحسب. مثلا ل"akronim " في اللغة الإندونيسية: (Universitas Islam Negeri) : UIN : RSUD ، GBHN (Garis-garis Besar Haluan Negara) ،(Rumah Sakit Umum Daerah) SDM (Sumber Daya Manusia)

2. لغة التصريف

الكلمة الواحدة في اللغة العربية نستطيع أن نصرّفها إلى اوزان الكثيرة حتى تجعل كلمة ست مائة كلمة جديدة، بمعاني الجديدة يختلف من معنى كلمة الأصل ولكن تشترك في المعنى العام الواحدة. ويتوفر فيه التصريف اللغوي كتصريف الفعل الماضي والفعل المضارع وفعل الأمر حسب ضميرها، مثلا: أحمد يكتب (Ahmad sedang menulis)، الطالبان يكتبـان ( Dua orang siswa sedang menulis الضمير.

وفي استعمال الفعل، لايوجد التغيير حسب الضمير في اللغة الإندونيسية كما في اللغة العربية كما في المثال السابق. وكذلك التصريف اللغوي، مثلا: تصريف الفعل الماضي "كتب" إلى اسم فاعل "كاتب" أو اسم مفعول "مكتوب". وأما في اللغة الإندونيسـة، كلمة واحدة تستطيع أن تغيّرها إلى إنى عدة كلمات فحسب على الأكثر خمسـة أو ستاة صيخ جديدة، وهذا في مقابل التصريف اللغوي في اللغة العربية، ولكن ليس هذا التصريف في اللغة الإندونيسية مستخدم لكل صيغةة، فمنها بزيادة كلمة أخرى أو أكثر. مثلا: Lihat alat untuk melihat dilihat kelihatannya penglihatan melihat-lihat - waktu melihat melihat tempat melihat 

Lugah al Indūnisiyyah (Fĩ al Mabānī al Șarfiyyah wa al Taräkīb al Naḥwiyyah wa al ma'anny al Dilāliyyah

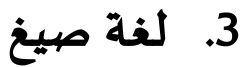

بناء الصيغ مع الاشتقاق أساسان لتوليد المفردات وإثراء اللغة. ويقصيد

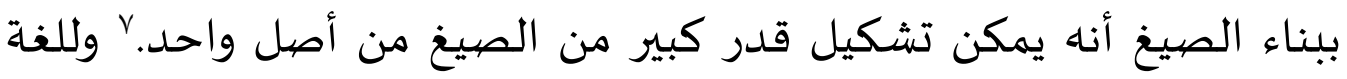
العربية صيخ كثيرة بالاوزان المعينة، حتى نعرف لغة العجم إذا تخالف الصيغ

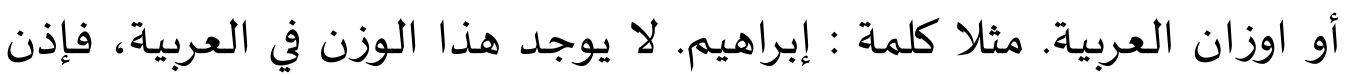

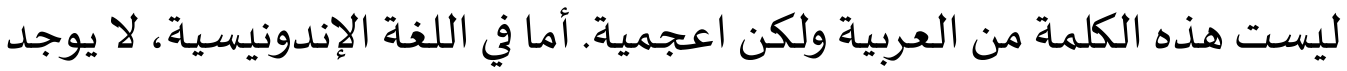

$$
\text { أمطابقة في صيخ صرفية الخاصة لها. }
$$

وهناك عدة معان صرفية عامة لها صيغة خاصة تؤدي بواسطة اللواصق، ومنها: الشخص (التكلم والخطاب والغيبة)، العدد (الافراد والتثنية

$$
\text { والجمع)، النوع (التذكير والتأنيث)، والتعيين (التعريف والتنكير). }
$$

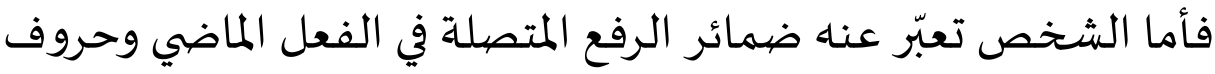

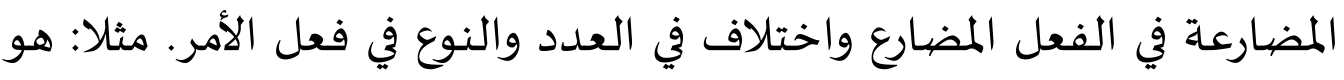

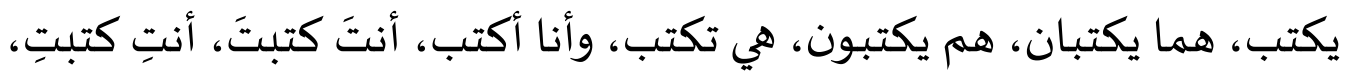

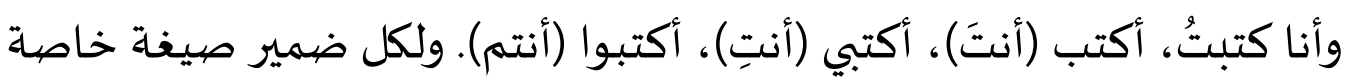

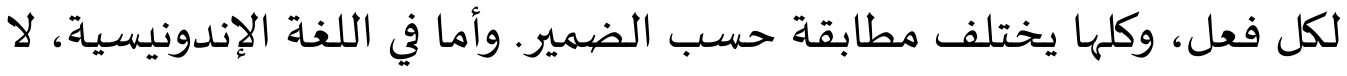

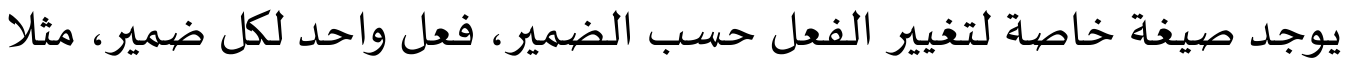

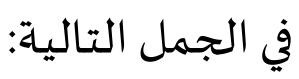

Saya menulis, Kamu laki-laki menulis, Mereka menulis, Kami menulis. Tulislah! (لكل ضمير مخاطب)

$$
\begin{aligned}
& \text { ب) العدد (الافراد والتثنية والجمع) } \\
& \text { > رشدي أحمد طعيمة، تعليم العربية لغير الناطقين بها مناهجه واساليبه ...، ص. } 36
\end{aligned}
$$

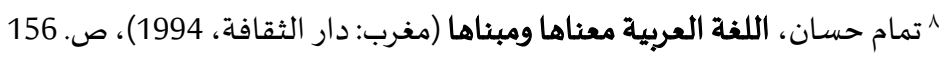



Lugah al Indūnisiyyah (Fĩ al Mabānī al Șarfiyyah wa al Taräkīb al Naḥwiyyah wa al ma'anny al Dilāliyyah

وهناك انواع الاسم من حيث عدده، وهي مفرد ومثنى وجمع. ويوجد في اللغة العربية صيغة خاصية أو شكل خاص لبناء المثنى والجمع، إلا لجمع التكسير. أما بناء المثنى فبزيادة "ألف ونون" أو "ألف وياء" في أخر مفرده، مثلا: مسلم (seorang muslim)، مسلمان أو مسلمَين (dua orang muslim). وأما بناء جمع المذكر السالم بزيادة "واو ونون" أو "ياء ونون" في آخر مفرده، مثلا: مسلم

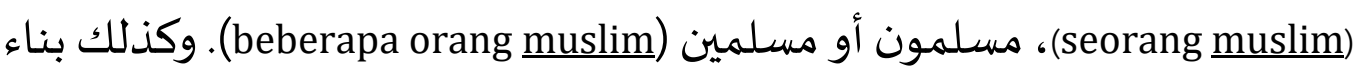
جمع المؤنث السالم بزيادة "ألف والتاء" في آخر مفرده، مثلا: مسلمة ( seorang beberapa orang (dua orang muslimah) (․uslimah (muslimah خاص لها، مثلا: قلم (sebuah pena)، قلمان (dua buah pena)، أقلام ( beberapa)

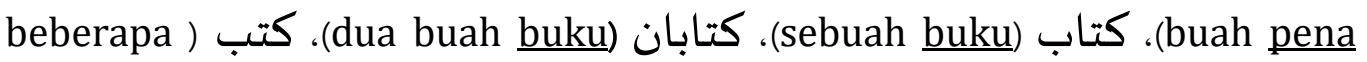

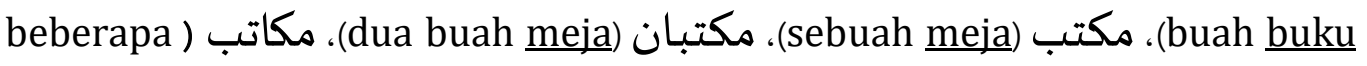
buah meja وأما في اللغة الإندونيسية لا يوجد تغيير صيغة أو شكل لكل اسم من مفرده حينما تغيّر عدده (كما في المثال السـابق)، مازالت الكلمة في صيغة مفرد، مثلا: (seorang muslim, dua orang muslim, beberapa orang muslim)

\section{ج) النوع (التذكير والتأنيث)}

هناك صيخ أو شكل خاص لتغيير الاسم حسب نوعاه. هناك انواع الاسم

من حيث جنساه وهي المذكر والمؤنث. لكل اسم في اللغة العربية يدخل إلى احد الفريقين، فريق اسم مذكر أو فريق اسم مؤنث. وعلامات التأنيث ثلاثة، وهي "التاء المربوطة"، مثلا: كراسـة، و"ألف مقصورة"، مثلا: حسنى، و"ألف ممدودة"، 

Lugah al Indūnisiyyah (Fĩ al Mabānī al Șarfiyyah wa al Taräkīb al Naḥwiyyah wa al ma'anny al Dilāliyyah

مثلا: اسماء. فالتاء المربوطة تلحق الصفات لتمييز بين المذكر والمؤنث، مثلا: طالب (siswa laki-laki)، طالبة (siswa perempuan)، مدرس (bapak guru)، مدرسـة (ibu guru)، كاتب (seorang penulis laki-laki)، كاتبة ( seorang penulis) perempuan اللغة الإندونيسية، لا يعرف تقسيم الاسم إلى المذكر والمؤنث. ويوجد فيها صيغة خاصية ليفرق بين اسم مذكر واسم مؤنث، ولكن بزيادة الكلمة الآخرى فحسب. مثلا:bapak guru, ibu guru

$$
\text { د) التعيين (التعريف والتنكير) }
$$

التعيين خاص للاسم. فالفرق بين النكرة في الأسماء في حالة التنكير وبينها في حالة التعريف هو الصاق "ال" بها في حالة التعريف. مثلا: جامة (نكرة)، الجامعة (معرفة)، طالب (نكرة)، الطالب (معرفة)، عين (نكرة)، العين (معرفة)، كتاب (نكرة)، الكتاب (معرفة)، قلم (نكرة)، القلم (معرفة). وأما في اللغة الإندونيسية لا يوجد الصاق في تعيين الاسم، ولكن التعيين فيها بزيادة الكلمة "itu/tersebut" بعد الكلمة المقصودة. مثلا: الطالب ( mahasiswa (itu/mahasiswa tersebut )، الجامعة (kampus itu/kampus) tersebut)، القلم .(pena itu/pena tersebut)

\section{خصائص العربية في التراكيب النحوية مقارنة باللغة الإندونيسية

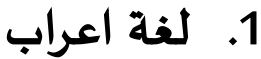

الإعراب أساس المعنى. ويقصد بالاعراب أن للغة قواعد في ترتيب

الكلمات وتحديد وظائفها وضبط أواخرها. وهذا مما يساعد على دقة الفهه. الاعراب هو: الابانة عن المعانى بالالفاظ، او اثر يجلبه العامل، وتغيّر العلامة 
Isra Hayati Darman: Khașāis al Lugah al 'Arabiyyah wa Khāsșah bi al Muqāranah bi al Lugah al Indūnisiyyah (Fĩ al Mabānī al Șarfiyyah wa al Taräkīb al Naḥwiyyah wa al ma'anny al Dilāliyyah

التى في آخر اللفظ بسبب التغير العوامل الدخلية علياه، أو تغيير اواخر الكلمات بتغيير وظائفها النحوية ضيمن الجملة. ' وهناك اختلاف الأراء في فائدة ودلالته. هل حركات التي تتعاقب على اواخر الكلمات هي اشـارات على المعاني المختلفة؟ قال الفريق الأول أن الحركات الزوائد يلحقن الحروف ليوصل إلى التكلم باه، إذن، لايفيد المعنى. ومن الرجال هذا الفريق خليل بن أحمد الفراهدي ومحمد بن المستنير أم مشهور بقطرب. وأما الفريق الثاني يرى أن هناك التفسير الدلالي للحركات وأن الإعراب يفارق بين المعاني في الألفاظ، ومنهم أبو قاسم الزجاجي وابن فارس."

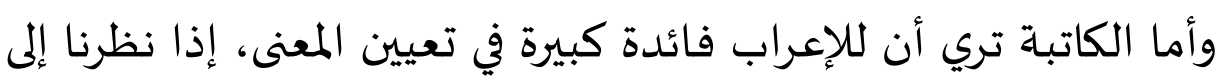
احدى الآيات القرآنية: ...إنما يخشى الله من عباده العلماء... (الفاطر: †^). الشكل الأخير الصحيح للفظ "الله" هو الفتحة، والشكل الصحيح للفظ "العلماء" هو الضممة. ولكن، إذا نبدل الشكل بينهما، فوقع إلى أخطاء كبيرة

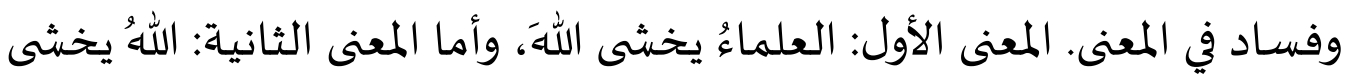
العلماءَ، هما يختلف كثيرا. أما في اللغة الاندونيسية لا يوجد الاعراب، لأنه هذا الإعراب خاص للغة العربية.

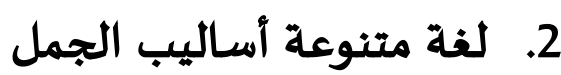

إن العربية ذات أنماط مختلفة للجملة. فهناك الجملة الإسمية والجملة الفعلية وهناك الجملة الخبرية والجملة الإنشائية. وهناك الجملة الإستفهامية والجملة الدعائية وغيرها.

·' إميل بديع يعقوب، فقه اللغة العربية وخصائصها ...، ص. 128

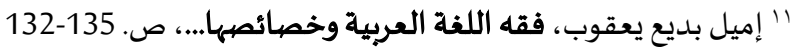
"' رشدي أحمد طعيمة، تعليم العربية لغير الناطقين بها مناهجه واساليبه .... ص. 36 
Isra Hayati Darman: Khașāis al Lugah al 'Arabiyyah wa Khāsșah bi al Muqāranah bi al Lugah al Indūnisiyyah (Fĩ al Mabānī al Șarfiyyah wa al Taräkīb al Naḥwiyyah wa al ma'anny al Dilāliyyah

الجملة في اللغة العربية تنقسم إلى نوعين، الجملة الفعلية والجملة الاسمية. شرح الغلاييني بأن الجملة الفعلية هي ما تألفت من الفعل والفاعل، مثلا: سبق السيف العذل، أو الفعل ونائب الفاعل، مثلا: يُنصر المظلوم، أو الفعل الناقص واسماه وخبره، مثلا: يكون المجتهد سعيدا. والجملة الاسمية هي ما كانت مؤلفة من المبتدأ والخبر، مثلا: الحق منصيور، ومما أصله المبتدأ

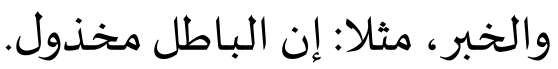

من خصائص الجملة الفعلية في اللغة العربية هي تبدأ بفعل ثم يتبعه الفاعل أو نائب الفاعل، مثلا: جاء فاضل (جاء: فعل، فاضل: فاعل) أو كُتب الدرسُ (كُتب: فعل، والدرس: نائب الفاعل). وأما الجملة الاسمية تبدأ باسم كالمبتدأ ثم يتبعه الخبر (اسم أو جملة اسمية أو جملة فعلية أو شبـه الجملة)، مثلا: هذا قلم (هذا: اسم: المبتدأ، قلم: الخبر). وأما الجملة في اللغة الإندونيسية تتكون من "subjek"، و" "prediket"، و"keterangan" و و"kebjek"، وتنقسم الجملة في اللغة الإندونيسية إلى " kalimat "kalimat verbal" و" "kalimat nominal" هي الجملة التي لها "prediket" بشكل "اسم" أو "صفةة" أو "ظرف/الحال". مثلا: "Ayahku petani"،

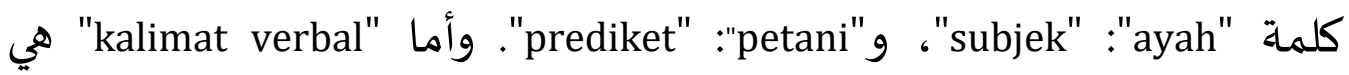
الجملة التي لها "prediket" بشكل "فعل"،؛ُمثلا: "Dia membaca novel"، كلمة "Dia" إذا تقارن بين الجملة الاسمية في اللغة العربية ب"kalimat nominal" في "subjek" اللغة الإندونيسية، ستوجد أن المبتدأ والخبر في الجملة الاسمية هما

ז' الشيخ مصطفى الغلاييني، جامع الدروس العربية، ج. 3 (بيروت: دار الكتب العلمية، 1944)، ص. 213 1 Siti Annijat Maimunah, Baahasa Indonesia untuk Perguruan Tinggi (Malang: UIN Maliki Press, 2011), h. 1112 
Isra Hayati Darman: Khașāis al Lugah al 'Arabiyyah wa Khāsșah bi al Muqāranah bi al Lugah al Indūnisiyyah (Fĩ al Mabānī al Șarfiyyah wa al Taräkīb al Naḥwiyyah wa al ma'anny al Dilāliyyah

و"kalimat nominal" في "kaliket". وكذلك إذا تقارن بين الجملة الفعلية في اللغة العربية ب"kalimat verbal" في اللغة الإندونيسية، ستوجد أن فعل وفاعل في الجملة الفعلية هما "subjek" و"prediket" في "kalimat verbal" ولكن بترتيب مختلف. يقع "الفعل" في الجملة الفعلية في أول الجملة قبل "الفاعل"، ولكن "kalimat verbal" يقع بعد "subjek" ئ "suliket". مثلا في الجملة الفعلية: ذهب فاضل إلى المدرسـة (فعل+فاعل+جر ومجرور)، وأما في "kalimat verbal" (subjek+prediket+keterangan) Fadhil pergi ke sekolah: إذن، الجملة الاسمية في اللغة العربية تبدأ باسم، والجملة الفعلية تبدأ بفعل، وأما "kalimat nominal" و"kalimat verbal" في اللغة الإندونيسية كلهما تبدأ باسم، ولا يوجد فيها الجملة التي تبدأ بفعل، إلا في "kalimat perintah"، مثلا: "Buanglah " " مersihkanlah kamarmu!" ،" Pergilah kamu ke sekolah! sampah pada tempatnya! والجملة أو الكلام في اللغة العربية ينقسم إلى قسمين : خبر وانشاء. فالخبر هو ما يصحّ أن يقال لقائله إنها صيادق فيه أو كاذب، فإن كان الكلام مطابقا للواقع كان قائله صادقا، وإن كان غير مطابق له كان قائله كاذبا. والإنشاء هو ما لا يصحّ أن يقال لقائله أنه صادق فيه أو كاذب. مُثال لكلام

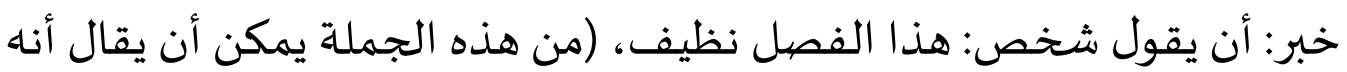
صادق أو كاذب حسب الواقع). ومثال لكلام إنشاء: أن يقول شخص: إفتح الباب! (من هذه الجملة، لا يمكن أن يقال أن القائل صيادق أو كاذب، لأن لا يوجد هذين العنصرين في هذه الجملة). وتتضمن في كلام إنشاء الأمر والنهي والإستفهام والنداء والتمني (يسمى بالإنشاء الطلبي)، والمدح والذم والصيغ العقود والتعجب والقسم والرجاء (يسمى بالإنشاء غير طلبي). 

Lugah al Indūnisiyyah (Fĩ al Mabānī al Șarfiyyah wa al Taräkīb al Naḥwiyyah wa al ma'anny al Dilāliyyah

وأما في اللغة الإندونيسية لا يوجد تقسيم الجملة أو الكلام كمثل هذا التقسيم، ولكن في تطيق الكام يوجد الجمل المشابهة في اللغة الإندونيسية بتقسيم المختلف، ومنها: "kalimat berita"، و"kalimat perintah"، و" kalimat tanya 3. لغة مطابقة في تراكيب النحوية والجمل في اللغة العربية، يعرف المصطلح "مطابقة"، وخاصية في التراكب النحوية والجمل العربية. ومنها التركيب الإسنادي، وهو مسند ومسند إلياه، وهذا التركيب ما يسمى بالجملة، وهو نوعين: الجملة الاسمية والجملة الفعلية. مطابقة في الجملة الاسمياة يشتمل على عنصر الجنس والعدد، مثلا: هذا كتاب، هذه كرّاسـة، هذان كتابان، هاتان كراستان. ومطابقة في الجملة الفعلية يشتمل على عنصر الجنس، ونوع الضيمير، مثلا: ذهب الطالب، ذهبت الطالبة، ذهب الطلاب، ذهبتُ، ذهبتِ، وغيرها. وكذلك في التركيب البياني في التعت والمنعوت، لابد أن يطابق بين النعت والمنعوت في الجنس والعدد والتعيين، مثلا: الكتاب الجديد، الكراسـة الجديدة، مدرسـة جميلة، قلمان جديدان، وغيرها. وأما في اللغة الإندونيسية، لا يوجد المطابقة كما في اللغة العربية، مثلا: " Ani ،"Ibu memasak" ،"Ayah memasak" ،"Budi pergi sekolah" ،"pergi sekolah ،"Kampus itu bagus" ،"Rumah itu bagus" ،"ini tiga pena" ،"ini satu pena" "Mobil itu bagus" ، وغيرها. وكلها بدون قواعد في المطابقة.

\section{خصائص العربية في المعاني الدلالية مقارنة باللغة الإندونيسية 1. المعاني الدلالية من ناحية الأصهوات \\ أ) فونيم}


Isra Hayati Darman: Khașāis al Lugah al 'Arabiyyah wa Khāsșah bi al Muqāranah bi al Lugah al Indūnisiyyah (Fĩ al Mabānī al Șarfiyyah wa al Taräkīb al Naḥwiyyah wa al ma'anny al Dilāliyyah

وهناك مجمل القول في معانى الفونيم، ومنها: الفونيم هو الوحدة المتميزة الصغرى التى يمكن تجزء سلسلة التعبير إليه. جورأي العالم الإنجليزى (دانيال جونز). وهو يتمشى مع الشرح السابق لكلمة ((صوت)) بمعنييه المختلفين. فالفونيم عنده (عائلة من الأصيوات المترابطة فيما بينها في الصفات في لغة معيينة والتى تستخدم بطريقة تمنع وقوع أحد الأعضاء في كلمة من الكلمات في نفس السياق الذى يقع فياه أى عضو آخر من العائلة نفسها). فالفتحات في العربية مثلا أعضاء الفونيم واحد، هي الفتحة ، بسبب اشتراكها في كثير من الصفات، ولكن اية فتحة منها لا تقع في موقع الأخرى. فالفتحة المفخمة في طاب لا تقع محل الفتحة المرققة في تاب أو العكس. من أهمية تعليم الأصيوات في اللغة العربية، أن لكل صوت أو فونيم له وظيفة فيتغيير المعنى من الكلمة، إذا أخطأ الشخص في نطق صوت أو فونيم معيين سيسبب انتقال من فونيم واحد إلى فونيم آخر، حتى يأثّر في المعنى. وهذا الصيوت أو الفونيم في اللغة العربية تتكون من الصيوائت والصيوامت. الصيوائت هي كل حركات في اللغة العربية وهي الضممة والفتحة والكسرة، والصروامت هي كل صيوت من الحرو الهجائية، وهي من "ألف" حتى "الياء".

هناك الكلمات العربية التي لها صوت متقارب وكثير من الدارسين يخطأ ويتبادل في استعمالها. مثلا: كلمة "قلب" وكلب"، كلمة "اسم" و"اثم"، كلمة "صواب" و"ثواب"، لكلها معنى خاصهة ويختلف بعضها بعضا. إذا قرأ الطالب لفظ " بسم الله الرحمن الرحيم" ب" بثم الله الرحمن الرحيم"، بتغيير صوت "سين" بصوت "ثاء"، وهذا النطق سيفسد المعنى من هذه الجملة الكريمة.

$$
\begin{aligned}
& 17 \text { أحمد مختار عمر، دراسة الههوت اللغوي، (القاهرة: عالم الكتب، 1997)، ص. } 161
\end{aligned}
$$

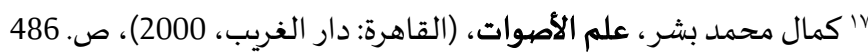



Lugah al Indūnisiyyah (Fĩ al Mabānī al Șarfiyyah wa al Taräkīb al Naḥwiyyah wa al ma'anny al Dilāliyyah

وأما مثال لتغيير المعنى بتغيير فونيم بشكل حركات هي: تغيير نطق

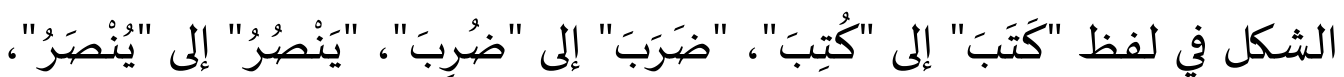
وغيرها. وهذه الكلمات حينما يقرأ بشكل مختلف ستختلف المعنى.

وأما في اللغة الإندونيسية لا يوجد تأثير كبير في تغيير فونيم في نطق الكلمات، لأن الحروف في اللغة الإندونيسية كلها يختلف بعضها بعضا. إلا في الكلمات المعينة، وهذا قليل جدا، مثلا كلمة "apel" التي تقرأ بطريقين، بترقيق في قراءة حرف "e"، وبتفخيمها، فالمعنى يختلف، أحدهما بمعنى "التفاحة" وآخر بمعنى "طقس". ب) مرفيم (morpheme) مرفيم في اللغة العربية هو الوحدة الصغرى لها معنى. وينقسم المرفيم إلى مرفيم حرّ ومرفيم مقيّد. مرفيم حرّ هو مرفيم الذي له معنى مستقل ولا يحتاج إلى غيره لإيجاد المعنى، ومرفيم مقيّد هو مرفيم الذي يحتاج إلى مرفيم حرّ في بناء المعنى، ولكن كلاهما يسبب في تغيير المعنى في الكلمات أو في الجملة. مثلا: الكلمة "يكتبون"، تتكون من ثلاثة مرفيمات، وهي مرفيم حرّ "كتب" و مرفيم مقيّد "ي"(حرف المضارعة)، ومرفيم مقيّد"ون" (علامة الجمع). مرفيم في اللغة الإندونيسية يسمى بـ "morfem". لله نفس المعنى بمرفيم في اللغة العربية، وهو وحدة الصغرى التى لله معنى. وله كذلك نفس التقسيم بتقسيم مرفيم باللغة العربية، وهما الأول المرفيم الحرّ "morfem bebas" (وهو morfem " مرفيم الذي يستقل بنفسـا في تأدياة المعنى)، والثاني المرفيم المقيد terikat (وهو مرفيم الذي لا يمكن أن يستقل بنفسـه في تأدياة المعنى، لأنها يحتاج إلى مرفيم الحر لبناء المعنى).'والمرفيم الحر هو الكلمة الأسـاسية

1 Masnur Muslich, Garis-garis Besar Tatabahasa Baku Bahasa Indonesia (Bandung: Refika Aditama, 2010), h. 12 
والمرفيم المقيّد هو "prefiks" (الأحرف الزيادات) الذي يتضمن فياه (الزيادة في أول الكلمة)، "infiks" (الزيادة في وسط الكلمة))، و"sufiks" (الزيادة في آخر الكلمةة). مثلا: الكلمة "menyimpulkan" تتكون من مرفيم حرّ "simpul" ومرفيم مقيّد "men" و"kan". ومثال آخر: الكلمة "menjelaskan" تتكون من

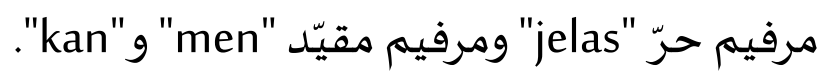

ج) النبر (stressing)

النبر في اللغة معناه البروز والظهور ومنه " المنبر" في المساجد ونحوها. وهذا المعنى العام ملحوظ في دلالته الاصطلاحية. إن هو في الدرس الصوتى يعنى نطق مقطع من مقاطع الكلمة بصورة أوضح وأجلى نسبيا من بقية المقاطع التى

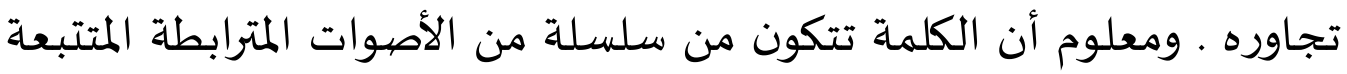
التى يسلم بعضها إلى بعض، ولكن هذه الأصيوات تختلف فيما بينها قوة وضعفا بحسب طبيعتها ومواقعها. فالصوت أو المقطع الذى ينطبق بصورة أقوى مما يجاوره يسمّى صيوتا أو مقطعا منبورا stressed، ويتطلب النبر عادة بذل طاقة في النطق أكبر ذسبيا، كما يتطلب من أعضياء النطق مجهودا أشـد . لايؤتي مدرسو اللغة العربية الإهتمام الكثير في النبر في عملية التعليم، التهاء إلا في المد، لأن الاخطأ في اعطاء النبر في الكلمة التي تتضمن فيه المد سيحمل إلى معان أخرى. فالنبر في اللغة العربية يستطيع أن يغيّر المعنى من الكلمة. مثلا: كلمة "مطر" (hujan)، إذا نؤتي النبر في "ط" فتجعل "مطار" (bandara)، فتغيّر المعنى، وكذلك كلمة "جمال" (kecantikan)، إذا نحذف منها النبر في "م" فتجعل "جمل" (unta)، بمعنى آخر. وفي اللغة العربية رمز خاص لهذا النبر لكل اوزان الكلمات.

أما في اللغة الإندونيسية، لا يوجد هذا النبر الذي يغيّر المعنى حقيقيا كما في اللغة العربية، إلا يقع التغيير في الإنفعالات أو الشعور من السـامع · إذا 

Lugah al Indūnisiyyah (Fĩ al Mabānī al Șarfiyyah wa al Taräkīb al Naḥwiyyah wa al ma'anny al Dilāliyyah

ينطق الشخص كلمة "buku"، بإعطاء النبر في أحد مقاطعها، فتجعل "buuku"، أو "bukuu"، ولن يغيّر المعنى، المعنى ثابت في المعنى الأصل، إلا يمكن تغيّر المعنى

$$
\text { الثانياة فيها حسب مقتضى الحال. }
$$

د) التنغيم (intonation)

ومن مظاهر الدلالة الصوتياة، ما نسمياه بالنغمة الكلامية أو التنغيم

intonation "لا يا شيخ؟!" يستطيع الشخص أن ينطق بها بعدة نغمات، وهي مع كل نغمة من وتن تلك النغمات تفيد دلالة خاصةة، فهي مرة لمجرد الاستفهام، وأخرى للتهكم

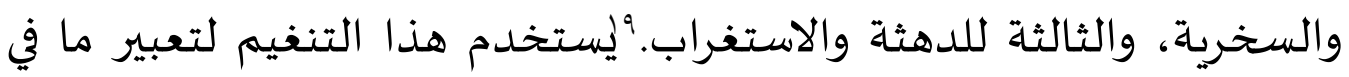
الفكرة أو في الشعور مباشرة في الكلام، فهذا التنغيم سيفهم الجملة الواحدة بعدة معان حسب تنغيمهنا!.

وأما في اللغة الإندونيسية يوجد كذلك التنغيم، بجملة واحدة نستطيع أن نفهم المعنى المتنوعة حسب التنغيم. مثلا الجملة: "ini siswa baru" إذا ينطق يوجق

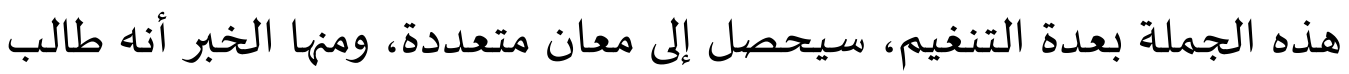
جديد، أو استفهام، لمعرفة الصدق من هذا الخبر، أو التهكم من الأصهدقاء لأن سبب معين فياه، أو غيرها.

\section{2. المعاني لدلالية من ناحية المفردات أ) الترادف}

الترادف أو المترادف في اللغة هو ما اختلف لفظه واتفق معناه، أو اطلاق عدة كلمات على مدلول واحد، كأسـد والسبع واللّيث وأسـامة، والتي مسمّى ماسي

$$
9 \text { إبراهيم أنيس، دلالة الألفاظ، (د.ع: د.م. 1958)، ص. } 47
$$

2 Ahmad Sayuti Anshari Nassution, Ilmu al-Ashwat al-Arabiyah. Jakarta: Amzah. 2010, h. 128 
Isra Hayati Darman: Khașāis al Lugah al 'Arabiyyah wa Khāsșah bi al Muqāranah bi al Lugah al Indūnisiyyah (Fĩ al Mabānī al Șarfiyyah wa al Taräkīb al Naḥwiyyah wa al ma'anny al Dilāliyyah

واحد.'وَاتفق ابن فارس في هذا التعريف، قال: ويسمى الشيء الواحد بالأَسماء المختلفة. نحو: "السيف والمهنّد والحسام".ّوَّكن اختلف العلماء في وقوع هذه الظاهرة في اللغة العربية مع أن الشواهد كثيرة في وجود هذه الظاهرة. ويوجد اسماء مترادفات الكثيرة في اللغة العربية ومن اسباباه هو اختلاف اللهجات

$$
\text { العربية حتى تجعل اللغة العربية لغة غنية في المفردات. }
$$

وأما الترادف يساوي ب"sinonim" في اللغة الإندونيسية، ويوجد في هذه اللغة كثيرا من "sinonim"، مثلا: كلمة "bisa" و"dapat"، "pandai" و" و" "pintar"

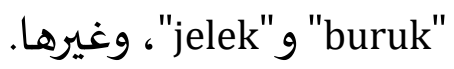

\section{ب) المشترك اللفظي}

المشترك اللفظي هو كل كلمة لها عدة معان حقيقية غير مجازية، أو هو اللفظ الواحد الدال على معنيين مختلفين فأكثر دلالة على السواء عند أهل اللغة. ومن أمثلتـا لفظ "الحوب" الذي يطلق على أكثر من ثلاثين معنى، منها:

الإثم والأخت والبنت والحاجة والمسكنة والهلاك والحزن والضرب، وغيرها. rٓ وهناك المفردات المشهورة لدى الدارسين مثلا: كلمة "غرب" بمعنى جهة ودلو، وغيرها. وأما في اللغة الإندونيسية،، يوجد "homonim"، وهو في نفس المعنى بالمشترك اللفظي، مثلا: كلمة "bisa" بمعنى يستطيع وعضو حية، وكلمة "genting" بمعنى ضرورة وسقف، وغيرها. ج) التضاد

هناك تعريفان المختلفان لتضياد. التعريف الأول التضياد عند القدماء هو الكلمات التى تؤدى إلى معنيين متضيادين بلفظ واحد، ككلمة "الجون" تطلق

"r إميل بديع يعقوب، فقه اللفة العربية وخصائصها .... ص. 173

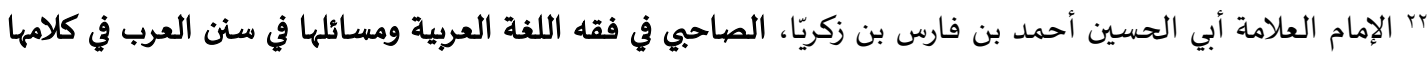

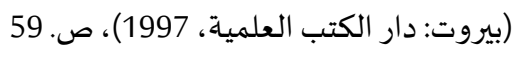

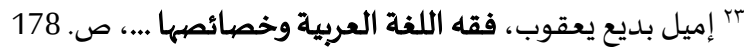



Lugah al Indūnisiyyah (Fĩ al Mabānī al Șarfiyyah wa al Taräkīb al Naḥwiyyah wa al ma'anny al Dilāliyyah

على الأسود والأبيض، و"الجلل" تطلق على الحقير والعظيم. عَفالتضياد بهذا التعريف نوع من المشترك اللفظي، التضياد أخص من المشترك اللفظي والمشترك اللفظي أعم من التضياد، كل التضياد هو المشترك اللفظي وليس العكس. المثال الآخر من التضـاد بهذا المعنى هو لفظ "قروء" التي يوجد في القرآن الكريم، يفسره العلماء إلى معنيين متضيادين، وهو الطهر والحيض، أو اللفظ "الظن" الذي يستعمل في معنيين متضيادين، فهما الشك واليقين. كما قال الله تعالى في السـورة الحجرات: "يا أيها الّذين آمنوا اجتنبوا كثيرا من الظن إن بعض الظن إثم ... (الحجرات: Y I)، وإنما المعنى: الشك. وقال الله تعالى في الآية الأخرى:"... إهها لكبيرة إلا على الخاشعين الذين يظنون أههم ملاقوا ربهم وأنهم إلياء راجعون (البقرة: 46-45) وإنما المعنى: يستيقنون (العلم واليقين). وأما عند علماء اللغة المحدثين التضاد هو وجود لفظين يختلفين نطقا ويتضادان معنى، كالقصير في مقابل الطويل والجميل في مقابل القبيح.وْهذا التعريف من التضاد يساوي بتعريف المصطلح الذي يسمى ب"antonim" في اللغة الإندونسية واللغة الإنجليزية. مثال في اللغة الإندونيسية لفظ "pendek" في مقابل "panjang"، لفظ "baik" في مقابل "buruk" وغيرها. إذن، تعريف التضاد في اللغة العربية عند المحدثين كتعريف "antonim" في اللغة الإندونيسية. أما التضاد بتعريف عند القدماء، لا يوجد في اللغة الإندونيسية، وهذا من خصائص اللغة العربية

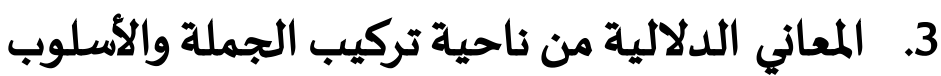
أ) اختلاف المعنى باختلاف وظائف الكلمات في الجملة

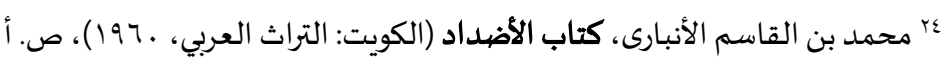

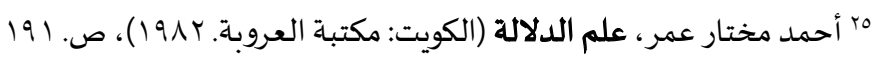



Lugah al Indūnisiyyah (Fĩ al Mabānī al Șarfiyyah wa al Taräkīb al Naḥwiyyah wa al ma'anny al Dilāliyyah

وظيفة الكلمة في الجملة المعينة سيعيّن معنى من تلك الجملة. إذ هناك جملتان تشتمل فيهما نفس الكلمات، ولكن المعنى ستختلف باختلاف وظائف هذه الكلمات في تلك الجمل. مثلا: ينصر عليّ عمرا، وينصر عليّا عمر. هاتان جملتان تتضهن الكلمات "ينصر" و"علي" و"عمر"، ولكن المعنى تختلف حينما يختلف وظائف من تلك الكلمات. في الجملة الأولى، وظيفة "علي" كالفاعل و"عمر" كمفعول باه، وعلى العكس في الجملة الثانية، وظيفة "علي" كمفعول باه و"عمر" كفاعل. وكذلك المثال من القرآن الكريم: ...إنما يخشى الله من عباده العلماء (الفاطر: r^). الشكل الأخير الصحيح للفظ "الله" هو الفتحة، وهو مفعول باء، والشكل الصحيح للفظ "العلماء" هو الضمةة، وهو فاعل. ولكن، إذا نبدل الشكل بينهما، فتغيّر وظيفتهما في تلك الجملة، فوقع إلى أخطاء كبيرة

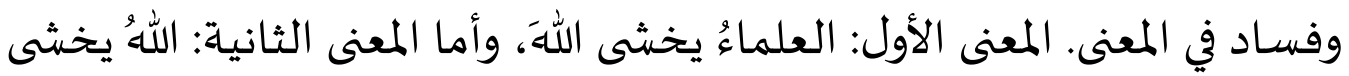
العلماءَ، هما يختلف كثيرا بإختلاف وظائف الكلمات. أما في اللغة الإندونيسية، يظهر اختلاف الوظائف الكلمات في الجملة Ali " بشكل واضح، لأن لا يوجد الإعراب في اللغة الإندونيسية. مثلا: جملتان "menolong Umar

\section{ب) اختلاف المعنى باختلاف السياق}

دراسة معاني الكلمات تتطلب تحليلا للسياقات والموقف التي ترد فيها، فمعنى الكلمات يتعدل تبعا لتعدد السياقت التي تقع فيها، أو بعبارة أخرى تبعا لتوزيعها اللغوي. وهناك اربعة انواع للسياق عند ك. أمّير، وهي: السياق اللغوي والسياق العاطفي والسياق الموقفي والسياق الثقافي.بr السياق اللغوي، فيمكن التمثيل له بكلمة "الكتاب". يتختلف معنى من هذه الكلمات حسب السياق اللغوي. لاحظ الجمل الآتية: "ذلك الكتاب لا ريب

$$
\text { Tr أحمد مختار عمر، علم الدلالة .... ص. } 69
$$



ma'anny al Dilāliyyah

فيه هدى للمتقين"، "يقرأ الطالب الكتاب في المكتبة"، "كان يهودي ونصارى من أهل الكتاب". فكل كلمة "الكتاب" في هذه الجمل تدل معان مختلفة لأن تدخل إلى سياق الجملة المختلفة.

فالمثال لاستعمال الكلمة في السياق الموقفي هو استعمال كلماة "يرحم". يقال "يرحمك الله" في مقام تشميت العاطس، ويقال "الله يرحم" في مقام الترحم بعد الموت. وأما المثل لاستعمال الكلمة في السياق العاطفي ككلمة "يكره" ويبغض"، لكلهما معنى العام الواحد ولكن فيهما عواطف مختلفة حينما يستعمل الشحص هاتين كلمتين. والمثال للسياق الثقفي هو استعمال كلمة "عقيلة" التي تعد في العربية المعاصرة علامة على الطبقة الاجتماعياة المتميزة بالنسبة إلى الكلمة "زوجة". وكذلك كلمة "جذر" لها معنى عند المزارع، ومعنى

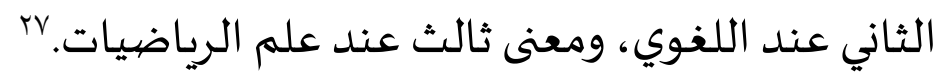
وأما في اللغة الإندونيسية يوجد هذه الاختلافات في السياق، وخاصة في السياق اللغوي والثقافي والعاطفي. مثلا في السياق اللغوي: هناك الكلماة: Ridwan " "baik" والجملة الجملة "Fadhil seorang pemuda yang baik" Kita telah " والجملة "merupakan salah satu dokter terbaik rumah sakit ini berhasil menciptakan produk yang terbaik عيناه وقدره وتحديده حسب السياق اللغوي. والمثال لاستعمال الكلمات في السياق الثقفي في اللغة الإندونيسية هو مدعو للأب في بعض مجتمع الإندونيسيا يختلف حسب طبقاتهم في المجتمع، هناك من يدعو أبياء بكلمة "abak" و"ayah" و"papa" و"papi" و وعادة تستعمل حسب درجـة الإقتصيادية في المجتمع المعين. وكذلك في السياق العاطفي، هنالك الكلمات "suka" و "senang" 

Lugah al Indūnisiyyah (Fĩ al Mabānī al Șarfiyyah wa al Taräkīb al Naḥwiyyah wa al ma'anny al Dilāliyyah

و"sayang" و"، لها معنى العام الواحد ولكن يختلف في استعمالها حسب العاطفة لدى المتكلم.

\section{ج) اختلاف المعنى حسب مقتضى الحال}

من مزايا اللغة العربية هي دقة التعبير واختلاف الأسـاليب بتنوع الأغراض والمقاصيد وأحوال المخاطب أو مقتضى الحال. وهناك ثلاثة أحوال المخاطب،^آلأول: إذا كان المخاطب خالي الذهن من الحكم، والخبر خاليا من أدوات التوكيد، مثلا: "الصلاة واجب" والثاني: إذا كان المخاطب مترددا في الحكم وينبغي للوصيول إلى اليقين في نعرفتاه، فيحسن لتوكيده لله ليتمكّن من نفسـاه، وازالة شكه، مثلا: "إن الصهلاة واجب" والثالث: إذا كان المخاطب منكرا لحكم الخبر، فلابد أن يؤكد له الخبر بمؤكد أو أكثر، مثلا: "والله الصهلاة واجب" أو "إن

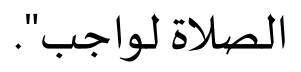

ولكن هناك كثرة استعمال الخبر الذي يخرج من مقتضى الظاهر لأن مقتضى الحال يختلف (هناك أحوال أخرى حول المخاطب التي تسبب المتكلم أن يستعمل اسـاليب المختلفة عن أحواله الظاهر. مثلا: قيل لمن ترك الصلاة: "إن الصلاة لواجب". في المقتضى الظاهر المخاطب لاينكر أن الصلاة واجب لكل مسلم، فأن يلقي الخبر بدون حرف التوكيد. ولكن لأنه لا يقيم هذه الواجبات فيضعاء المتكلم كأنه منكرا لهذا الخبر. وهذا من أمثلة اختلاف المعنى حسب مقتضى الحال أو أحوال المخاطب. وكذلك في كلام الإنشاء، كما قال العرب "لكل مقام مقال"، فالمعنى من اسلوب معين سيخلف حسب المقام أو الأحوال المخاطب. مثلا: معنى الأصل

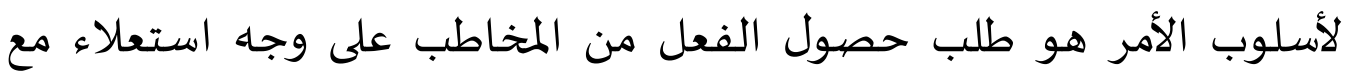



Lugah al Indūnisiyyah (Fĩ al Mabānī al Șarfiyyah wa al Taräkīb al Naḥwiyyah wa al ma'anny al Dilāliyyah

إلزام، وأي واجب. ولكن يخرج هذا الأسلوب من معناه الأصل لاختلاف مقتضى الحال، كقوله تعالى: "وكلوا واشربوا حتى يتبين لكم الخيط الأبيض من الخيط الأسـود من الفجر" (البقرة: INV). ومعنى صيغة الأمر في هذه الآية "وكلوا واشربوا" ليس المعنى الأصلي يعني إلزام أو واجب، ولكن المنعى هنا الإباحة. وأما في اللغة الإندونيسية،، لا يوجد الأسلوب كمثل هذا في استعمالها المتعددة ومعان متنوعة.

\section{د) تعبير عن المعنى بطرق متنوعة}

في علم البيان، هناك عدة طرق وأساليب في تعبير المعنى الواحد، وهي بأسلوب التشبيه والمجاز والكناية. مثلا إذا نريد أن نصوّر عن شجّاعاة رجل، فنقول في التشبيه: "عمر كالأسد"، ونقول في المجاز: "رأيت أسدا يخطب في المسجد"، ونقول في الكناياة: "في ثوبه أسـد". فكل كلمة "أسد" في هذه الأسـاليب يدل على صفة شجاعـة. وفي اللغة الإندونيسية يشاباه هذه الأساليب الثلاثة بأسلوب واحد المشهور باسم "perumpamaan"، مثلا: "Umar itu pemberani bagaikan singa". ه) هإ إيجاز الجملة العربية مشهورة بإيجازه. وأما الإيجاز فهو وضع المعاني الكثيرة في ألفاظ أقل منها، وافية بالغرض المقصود مع الإبانة والإفصاح. ‘مثلا قوله تعالى: "ألا له الخلق والأمر" (الأعراف: 54). تتضمن هذه الآية الجملة القصيرة والكلمات القليلة، ولكن هي تشتمل معاني الكثيرة فيها، هذه الآية القصيرة يتضمن فيها الشرح الكامل أن الله كل ما يتعلق بأي خلق في الدنيا والآخرة، في

$$
\begin{aligned}
& \text { r9 السيد أحمد الهاشمي، جواهر البلاغة ...، ص. } 64 \\
& \text { r السيد أحمد الهاشمي، جواهر البلاغة .... ص. } 193
\end{aligned}
$$



Lugah al Indūnisiyyah (Fĩ al Mabānī al Șarfiyyah wa al Taräkīb al Naḥwiyyah wa al ma'anny al Dilāliyyah

السماء والأرض، ومنها الناس والحيوان والنباتات والهواء والتراب والمياه والشمس والقمر والنجوم والكواكب حتى الجنة والنار، كلها يتضمن في هذه الأيية، وكذلك كل ما يتعلق بأمر كل شيء في السماء والأرض والدنيا والآخرة، وقت ميلاد المخلوق أو موتهم، وقت بداية الأرض والسماء، وقت طلوع الشمس وغربها، وغيرها، كلها من أمر الله وحده. أما حالة اللغة الإندونيسية ولغات ولهات أخرى ليس كمثل هذه اللغة العريماة.

\section{الخلاصة}

اللغة العربية لها خصائص كثيرة وخاصية بمقارنة باللغة الإندونيسية، من جهة الأصوات والمفردات والمباني الصرفية والتراكيب النحوية والمعاني الدلالية. من خصائص اللغة العربية في المباني الصرفية، أنها مشهورة بلغة اشتقاق، ولغة التصريف، ولغة الصيخ ولغة المطابقة في صيخ الصرفية (من جهة الشخص والعدد والنوع والتعيين). وأما خصائص اللغة العربية في التراكيب النحوية منها أنها مشهورة بلغة إعراب ولغة متنوعة أساليب الجمل ولغة مطابقة في تراكيب النحوية والجمل (حسب الضيمير والجنس في الجملة الفعلية وحسب الجنس والعدد في الجملة

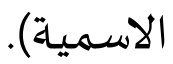

وأما خصائص اللغة العربي في المعاني الدلالية فتنقسم الباحثة إلى ثلاثة أقسام، هي: الأول: المعاني الدلالية من ناحية الأصيوات، وفيها فونيم ومرفيم والنبر والتنغيم، والثاثي: المعاني الدلالية من ناحية المفردات، يتضمن فيها الترادف والمشترك اللفظي والتضاد، والثالث: المعاني الدلالية من ناحية تركيب الجملة والأسلوب، ومنها إختلاف المعنى بإختلاف وظائف الكلمات في الجملة، وإختلاف المعنى بإختلاف السياق، واختلاف المعنى حسب مقتضى الحال، والتعبير عن المعنى بطرق متنوعاة، وإيجاز في اللغة العربية. 
Isra Hayati Darman: Khașāis al Lugah al 'Arabiyyah wa Khāsșah bi al Muqāranah bi al Lugah al Indūnisiyyah (Fĩ al Mabānī al Șarfiyyah wa al Taräkīb al Naḥwiyyah wa al ma'anny al Dilāliyyah

\section{الاقتراحات}

وهكذا من بعض الخصائص اللغة العربية وخاصة بمقارنة باللغة

الإندونيسية من جهة المباني الصرفية والتراكيب النحوية والمعاني الدلالية. ولكن هذا البحث بحث صغير وغير عميق، لأن لا يمكن أن يبحث كل الخصيائص الكثيرة من هذه اللغة في البحث الصغير والوقت القليل. فالبحث عن هذه الخصيائص لا يحدد فيما كُتبب في هذا البحث، ولكن يحتاج إلى الشرح الكثير والعميق فيها. ولذلك فيمكن للباحثين الآخرين أن يبحثوا عناصر من هذا البحث عنصرا فعنصرا حتى يكون البحث دقيق وعميق في علمـاء.

\section{المراجع}

أنيس، إبراهيم. دلالة الألفاظ. د.ع: د.م. 1958

عمر، أحمد مختار.دراسة الهرت اللغوي. القاهرة: عالم الكتب. 1997 1919 r علم الدلالة. الكويت: مكتبـة العروبة.

أبي الحسين أحمد بن فارس بن زكريّا. الصاحبي في فقه اللغة العربية ومسائلها في سنن العرب في كلامها. بيروت: دار الكتب العلمياة. 1997 يعقوب، إميل بديع. فقه اللغة العربية وخصائصها. بيروت: دار العلم للملايين. 1982

حسان، تمام. اللغة العربية معناها ومبناها. مغرب: دار الثقافة. 1994 طعيمة، رشدي أحمد. تعليم العربية لغير الناطقين بها مناهجه واساليبه. الرباط: منشورات المنظمة الإسلامية للتربية والعلوم والثقافة-ايسيسكو-. 1989 الهاشي، السيد أحمد. جواهر البلاغة. بيروت: دار الفكر. 1994 الجارمي، على ومصطفى أمين. البلاغة الواضحة. دم: دار المعارف. د.ع. بشر، كمال محمد. علم الأصهوات. القاهرة: دار الغريب. 2000 
Isra Hayati Darman: Khașāis al Lugah al 'Arabiyyah wa Khāsșah bi al Muqāranah bi al Lugah al Indūnisiyyah (Fĩ al Mabānī al Șarfiyyah wa al Taräkīb al Naḥwiyyah wa al ma'āny al Dilāliyyah

$$
\text { الأنبارى، محمد بن القاسم. كتاب الأضهاد. الكويت: التراث العربي. . } 197
$$

Maimunah, Siti Annijat. Bahasa Indonesia untuk Perguruan Tinggi. Malang: UIN Maliki Press. 2011

Muslich, Masnur. Garis-garis Besar Tatabahasa Baku Bahasa Indonesia. Bandung: Refika Aditama. 2010

Nasution, Ahmad Sayuti Anshari. Ilmu al-Ashwat al-Arabiyah. Jakarta: Amzah. 2010 